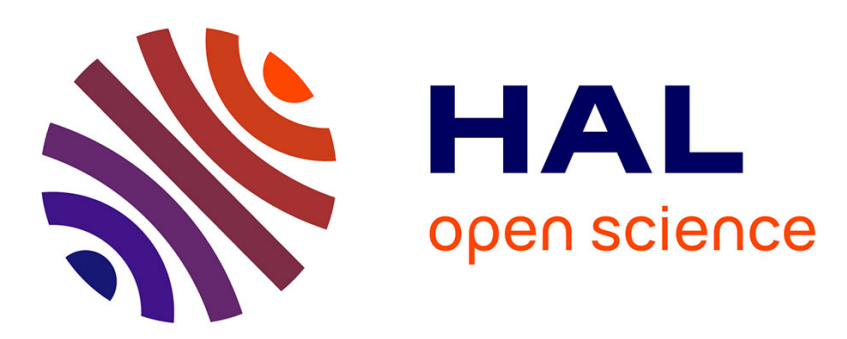

\title{
A numerical algorithm for inverse problems in photothermal detection
}

\author{
J.-C. Cheng, S.-Y. Zhang
}

\section{To cite this version:}

J.-C. Cheng, S.-Y. Zhang. A numerical algorithm for inverse problems in photothermal detection. Journal de Physique IV Proceedings, 1994, 04 (C7), pp.C7-559-C7-562. 10.1051/jp4:19947131 . jpa00253186

\section{HAL Id: jpa-00253186 https://hal.science/jpa-00253186}

Submitted on 1 Jan 1994

HAL is a multi-disciplinary open access archive for the deposit and dissemination of scientific research documents, whether they are published or not. The documents may come from teaching and research institutions in France or abroad, or from public or private research centers.
L'archive ouverte pluridisciplinaire HAL, est destinée au dépôt et à la diffusion de documents scientifiques de niveau recherche, publiés ou non, émanant des établissements d'enseignement et de recherche français ou étrangers, des laboratoires publics ou privés. 


\title{
A numerical algorithm for inverse problems in photothermal detection
}

\author{
J.-C. Cheng and S.-Y. Zhang \\ Institute of Acoustics and Laboratory of Modern Acoustics, Nanjing University, Nanjing 210008, China
}

\begin{abstract}
An iterative algorithm for solving nonlinear inverse problems in the photothermal detection is presented. The basic idea of the algorithm is that the nonlinear inverse problem in the frequency domain is solved by a hybrid of Newton-like iterative method, pseudoinverse technique, and finite difference method. The numerical simulation shows the algorithm is effective for profile reconstruction of the thermal conductivity in the case of errorless data.
\end{abstract}

\section{INTRODUCTION}

Photothermal depth profiling of inhomogeneous solids is important for the quantitative nondestructive evaluation (QNDE) of materials and devices. Recently, Mandelis et al [1] have presented a numerical algorithm of the thermal-wave frequency-domain depth profiling for continuously inhomogeneous condensed phases by means of a self-adjusting method.

In this paper, we present an iterative algorithm for solving nonlinear inverse problems in the photothermal depth profiling of inhomogeneous solids, which have arbitrary, continuously varying thermal conductivity profiles, by employing the pulsed spectrum technique (PST)[2]. The basic idea of the algorithm is that the nonlinear inverse problem in the frequency domain is solved by a hybrid of Newton-like iterative method, pseudoinverse technique, and finite difference method. The first kind Fredholm integral equation deduced in the iterative process is discretized by the finite rank approximation into algebraic equations, which are solved by the singular value decomposition method. The numerical simulation shows the algorithm is effective for profile reconstruction of the thermal conductivity in the case of errorless data.

\section{ITERATIVE ALGORITHM}

For an optically opaque solid sample with continuously varying thermal conductivity $\kappa(\mathrm{z})$, density $\rho(\mathrm{z})$, and specific heat $\mathrm{c}(\mathrm{z})$, the one-dimensional thermal diffusion equation in the frequency domain is,

$$
\frac{d}{d z}\left[\boldsymbol{\kappa}(z) \frac{d}{d z} T(z, \omega)\right]-i \rho(z) C(z) T(z, \omega)=0, \quad(0<z<L)
$$

with the boundary conditions at $\mathrm{z}=0$ and $\mathrm{L}$, 


$$
\begin{aligned}
-\kappa(0) \frac{d}{d z} T(z, \omega) & =g(\omega), \\
\kappa(L) \frac{d}{d z} T(z, \omega)=0, & \text { at } z=0
\end{aligned}
$$

where $T(z, \omega)$ is a Fourier transform of the time-dependent temperature variation $T(z, t), g(\omega)$ is a Fourier transform of the heat source $g(t), L$ is the thickness of the sample. In photothermal experiments, the temperature $T_{0}\left(\omega_{i}\right)$ at the sample surface $z=0$ can be detected at frequencies $\left\{\omega_{i}\right\}$,

$$
T\left(z, \omega_{i}\right)=T_{0}\left(\omega_{i}\right), \quad z=0 \quad(i=1,2,3, \ldots \ldots M)
$$

Now, the inverse problem is to determine $\kappa(z)$ and $\rho(z) c(z)$ from the known experimental data $T_{0}\left(\omega_{i}\right)$ for a set $\left\{\omega_{i}\right\}$ by the Eqs.(1) and (2). For simplicity, we suppose that the $\rho(z) c(z)$ is constant, and only the thermal conductivity $\kappa(\mathrm{z})$ depends on the depth $z$. According to PST method, we can construct a Newton-like iterative process,

$$
\begin{aligned}
& T_{k+1}(z, \omega)=T_{k}(z, \omega)+\delta T_{k}(z, \omega) \\
& \boldsymbol{\kappa}_{k+1}(z)=\mathbf{k}_{k}(z)+\delta \boldsymbol{\kappa}_{k}(z)
\end{aligned}
$$

Substituting Eq.(4) into Eqs.(1) and (2), we can obtain iterative equations,

$$
\begin{array}{ll}
\frac{d}{d z}\left[\kappa_{k}(z) \frac{d}{d z} T_{\kappa}(z, \omega)\right]-i \omega \rho c T_{k}(z, \omega)=0, \quad(0<z<L) \\
-\kappa_{k}(0) \frac{d}{d z} T_{k}(z, \omega)=g(\omega), \quad \text { at } z=0 \\
\kappa_{k}(L) \frac{d}{d z} T_{k}(z, \omega)=0, \quad \text { at } z=L
\end{array}
$$

and

$$
\begin{gathered}
\frac{d}{d z}\left[\kappa_{k}(z) \frac{d}{d z} \delta T_{k}(z, \omega)\right]-i \omega \rho c \delta T_{k}(z, \omega)=-\frac{d}{d z}\left[\delta \kappa_{k}(z) \frac{d}{d z} T_{k}(z, \omega)\right], \quad(0<z<L) \\
-\kappa_{k}(0) \frac{d}{d z} \delta T_{k}(z, \omega)=-\delta \kappa_{k}(0) \frac{d}{d z} T_{k}(z, \omega), \quad \text { at } z=0 \\
\kappa_{k}(L) \frac{d}{d z} \delta T_{k}(z, \omega)=-\delta \kappa_{k}(L) \frac{d}{d z} T_{k}(z, \omega), \quad \text { at } z=L
\end{gathered}
$$

By using the method of Green's function [3], one obtains a Fredholm integral equation of the first kind to determine $\delta \kappa_{\mathbf{k}}(\mathrm{z})$,

$$
\int_{0}^{L} \delta \kappa_{k}(\xi)\left[\frac{d T_{k}(\xi, \omega)}{d \xi}\right]^{2} d \xi=g(\omega)\left[T_{k}(0, \omega)-T_{0}(\omega)\right]
$$

Now the inverse problem is reduced to the determination of $\delta \kappa_{\mathrm{k}}(z)$ for each iteration from a set of measured data $\left\{\mathrm{T}_{\mathrm{o}}\left(\omega_{\mathrm{i}}\right)\right\}, \mathrm{i}=1,2,3, \ldots \mathrm{M}$. These measured data are used as the input data to right-hand side of Eq.(7) for the purpose of accelerating the rate of convergence. Because the first kind Fredholm integral equation is ill-posed, and usually the solution is not unique and does not depend continuously on the measured data, it is equivalent to solve Eq.(7) to constructing approximate solutions from the inadequate data with or without statistical measurement errors. Thus we employ the method of finite rank approximation to discretize Eq.(7) into algebraic equations, and then use the method of singular value decomposition to construct a least square solution.

Expanding $\delta \kappa_{\mathrm{k}}(\mathrm{z})$ by a normalized and orthogonal function series $\left\{\phi_{\mathrm{j}}(\mathrm{z}), \mathrm{j}=1,2,3 \ldots \mathrm{N}\right\}$, 


$$
\delta \kappa(z)=\sum_{j=1}^{N} K_{j} \phi_{j}(z)
$$

and taking frequencies $\left\{\omega_{i}, i=1,2,3 \ldots \mathrm{M}\right)$, one can obtain the algebraic equations to determine the coefficient $\left\{K_{j}, j=1,2,3, \ldots . N\right)$,

$$
\begin{gathered}
\sum_{j=1}^{N} a_{i j} K_{j}=g_{i}(\omega)\left[T_{k}\left(0, \omega_{i}\right)-T_{0}\left(\omega_{i}\right)\right] \\
i=1,2,3, \ldots M
\end{gathered}
$$

where

$$
a_{i j}=\int_{0}^{z}\left[\frac{d T_{k}\left(\xi, \omega_{i}\right)}{d z}\right]^{2} \Phi_{j}(\xi) d \xi
$$

This is a set of $\mathrm{MxN}$ of linear algebraic equations. The matrix $A$ with elements $\mathrm{a}_{\mathrm{ij}}$ $(i=1,2,3 \ldots M, j=1,2,3 \ldots N)$ can be represented by the singular value decomposition,

$$
A=U\left[\begin{array}{ll}
\mathbf{\Sigma} & 0 \\
0 & 0
\end{array}\right]^{T}
$$

where $\mathrm{U}$ and $\mathrm{V}$ are orthonormal matrices, $\Sigma=\operatorname{diag}\left(\sigma_{1}, \sigma_{2}, \ldots, \sigma_{\mathrm{r}}\right) \quad(\mathrm{r} \leq \min \{\mathrm{m}, \mathrm{n}\}$, and $\left.\sigma_{1} \geq \sigma_{2} \geq \ldots \geq \sigma_{\mathrm{z}}>0\right)$, and $\sigma_{\mathrm{i}}(\mathrm{i}=1,2,3 \ldots \mathrm{r})$ are the singular values of the matrix A. By Eq.(11), one can obtain a least square solution of the Eq.(9),

$$
K=V \Sigma^{-1} U^{T_{B}}
$$

where $K$ and $B$ are the column vectors with elements $K_{j}(j=1,2,3 \ldots N)$ and $B_{i}=g\left(\omega_{i}\right)\left[T_{k}\left(0, \omega_{j}\right)-T_{o}\left(\omega_{j}\right)\right]$, respectively.

\section{NUMERICAL SIMULATIONS}

The iteration procedure of the numerical simulation is as follows,

(I) First, a typical conductivity profile $\kappa(z)$ is assumed. The corresponding surface temperature $\mathrm{T}_{0}\left(\omega_{\mathrm{i}}\right)$ are obtained from Eq. (1) for a set of angular frequency $\left\{\omega_{i}\right\}, i=1,2,3 \ldots \mathrm{M}$, in which the two-point boundary value problem is solved by using the finite difference method as the equivalent of the measured data.

(II) Then, the initial distribution $\kappa_{0}(\mathrm{z})$ is assumed. The $\mathrm{T}_{\mathrm{o}}\left(\mathrm{z}, \omega_{\mathrm{i}}\right)$ are determined from Eq.(5) by using the same numerical methods as those of Step $I$, then the $a_{i j}$ and $B_{i}$ are obtained.

(III) Finally, $\delta \kappa_{\mathrm{o}}(\mathrm{z})$ is obtained from Eqs.(8-12) by using the linear inversion technique of the PST. Hence, from Eq.(4), $\kappa_{1}(z)$ is obtained.

(IV) The norm

$$
\int_{0}^{\Sigma}\left[\kappa_{k+1}(z)-\kappa_{k}(z)\right]^{2} d z<\epsilon
$$

can be used as a criterion for evaluating the performance of the numerical algorithm consisting of Steps II and III. If the desired accuracy is not met, then one can repeat Steps II and III until the desired 
accuracy is achieved.

It is worth to point out that Eq.(9) is complex coefficient equations, but the $\kappa(\mathrm{z})$ is real, so a prior knowledge can be used, i.e., the imaginary of $\delta \kappa(z)$ must be equal to zero. Hence one can divide the Eq.(9) into $2 \mathrm{M} \times \mathrm{N}$ algebraic equations by taking apart the real and imaginary parts, which will reduce the measured numbers of frequency.
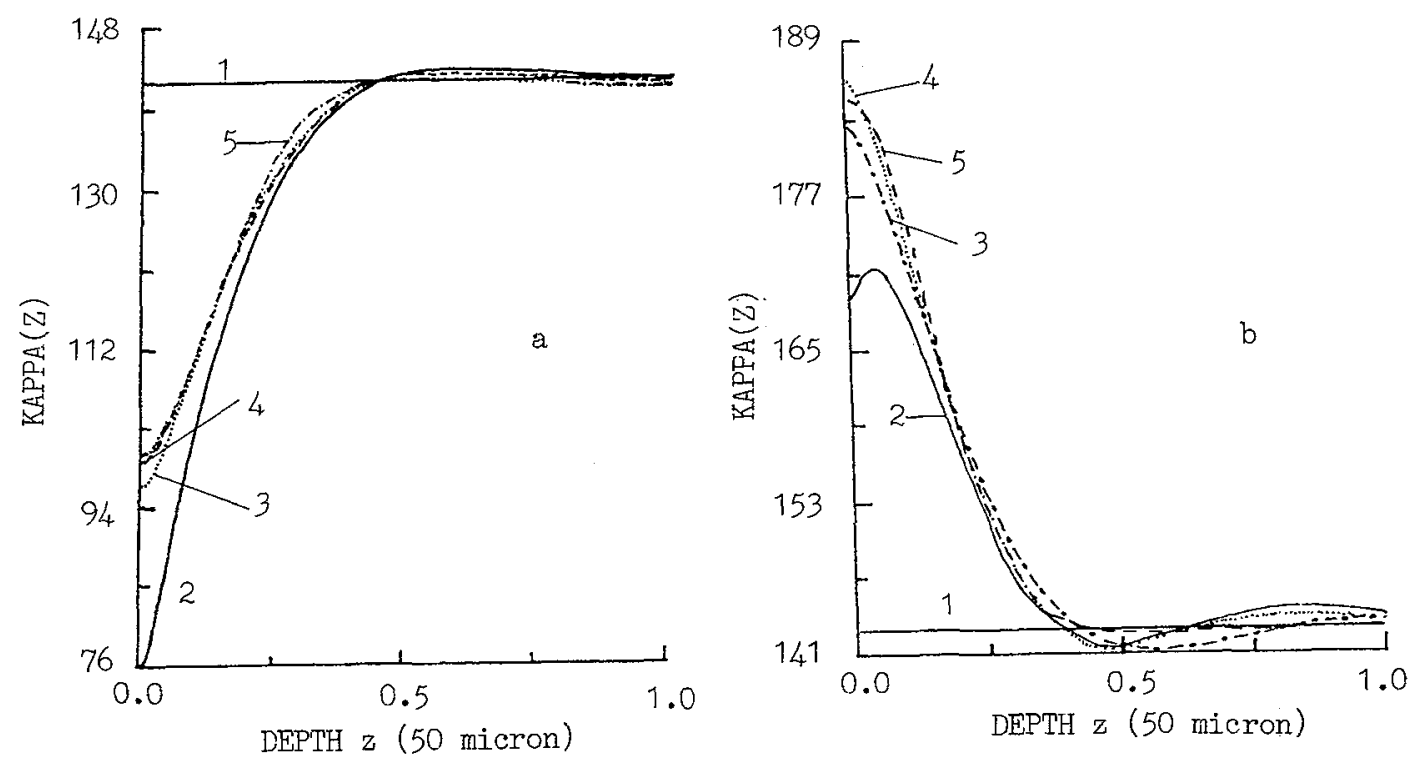

Fig. 1 Reconstructions of $\kappa(z)$, as $\kappa(z)$ is in increased (away) or decreased (1b) profile. Curves 1-4 represent $\kappa_{0}(\mathrm{z}), \kappa_{1}(\mathrm{z}), \kappa_{2}(\mathrm{z}), \kappa_{3}(\mathrm{z})$, and Curve 5 is exact $\kappa(\mathrm{z})$ profile in (1a) and (1b).

In the simulations, the function series $\left\{\phi_{j}(\mathrm{z})\right\}$ takes a simpler form,

$$
\phi_{j}(z)=\left[\begin{array}{cc}
\sqrt{N / L}, & \text { for } j L / N<z<(j+1) L / N \\
0, & \text { for other } z
\end{array}\right.
$$

and $2 M=150$ and $N=100$. The initial distribution $\kappa_{0}(z)$ is equal to constant. The algorithm has been implemented on personal computer. Fig.(1) depict the numerical simulations in the case of errorless data for increased or decreased profile. The results show that $\kappa_{\mathrm{k}}(\mathrm{z})$ can converge rapidly to the $\kappa(\mathrm{z})$. The further works about effects of noise on the accuracy and efficiency of the algorithm are in progress.

[1] A.Mandelis, S.B.Peralta, and J.Thoen, J. Appl. Phys., 70(1991)1761

[2] Y.M.Chen and J.Q.Liu, J. Comp. Phys., 43(1981)315.

[3] I. Stakgold, "Boundary Value Problem of Mathematical Physics," Vol.I, Macmillan, New York, 1967. 